\title{
Ellis Van-Creveld Syndrome in an Ethnic Group in Nepal: Case Report With Review of Literature
}

\author{
Gauchan $E^{1}$, Sharma $P^{2}$
}

${ }^{1}$ Dr. Eva Gauchan, MBBS, MD. Department of Paediatrics. ${ }^{2}$ Dr. Prakash Sharma, MBBS, MD. Department of Radiology and Imaging. Both from the Manipal College of Medical Sciences, Fulbari, Pokhara, Nepal

\section{Address for correspondence: \\ Dr. Eva Gauchan \\ E-mail: evagauchan@gmail.com}

\section{How to cite}

Gauchan E, Sharma P. Ellis Van-Creveld Syndrome in an Ethnic Group in Nepal: Case Report With Review of Literature. J Nepal Paediatr Soc 2016;36(2):188-192.

doi: http://dx.doi.org/10.3126/jnps.v36i2.15450

This work is licensed under a Creative Commons Attribution 3.0 License.

\begin{abstract}
Ellis van-Creveld syndrome is a rare autosomal recessive disorder characterized by acromesomelic dwarfism, postaxial polydactyly, oro-dental abnormalities and congenital heart disease. We are reporting three cases in two families of the same ethnic group from Western Nepal. Genetic testing should be done in this population in order to identify the mutation in the gene causing the syndrome.
\end{abstract}

Key words: Ellis van-Creveld syndrome, ethnic groups,Nepal

\section{Introduction}

E Ilis van-Creveld syndrome is a rare autosomal recessive disorder comprising of abnormalities of the ectodermal, mesodermal and endodermal derivatives. Characteristic features are disproportionate short stature, postaxial polydactyly, hypoplastic nails, hypodontia, conical teeth, harelip, multiple frenula attaching the alveolar margin to the inner side of lips and heart defects ${ }^{1}$. We report three cases in two families of the same ethnicity from Western Region of Nepal. This will be the second report of the case from a Nepalese family; the first being from a Gurkha family reported from Hong Kong².

Case 1: A 17 month old female, an only child of unaffected parents, with normal developmental history was brought to the Pediatric department for respiratory symptoms. She was born out of nonconsanguinous union at term with a birth weight of $2.5 \mathrm{~kg}$. Her present weight was $7 \mathrm{~kg}\left(<3^{\text {rd }}\right.$ percentile for age); length $74 \mathrm{~cm}$ ( between $3^{\text {rd }}$ and $10^{\text {th }}$ percentile); weight/length $<3^{\text {rd }}$ percentile; head circumference $44 \mathrm{~cm}$ ( $3^{\text {rd }}$ to $10^{\text {th }}$ percentile). General physical examination revealed flat nasal bridge, high-arched palate, bilateral hexadactyly of hands (Figure 1), small phalanges, short limbs, absence of medial and lateral incisors, conical peg-shaped teeth, fusion of the middle part of the upper lip to the maxillary gingival margin creating a V-shaped upper lip, small dysplastic nails and long narrow thorax. Radiological investigations showed acromesomelia with flaring of metaphysis of lower ends of long bones, absence of terminal phalanges of hands, absence of carpal bones, bilateral postaxial polydactyly in hands with polymetacarpalia, flattened ilium with left tibial exostosis, delayed appearance of distal fibular ossification centres, normal skull and spine. Echocardiogram and abdominal ultrasound examination were normal. 
Case 2:A newborn baby was admitted to the neonatal intensive care unit at 12 hours of life for severe respiratory distress. The baby was born to a 34 year old mother out of non-consanguinous marriage at term gestation by vaginal delivery with clear amniotic fluid. Family history showed an elder sister (Case 3) having short stature with dysmorphisms. There was a history of similar dysmorphisms in the paternal uncle's male child who had died at six months of age, apparently due to a cardiac defect and heart failure. Weight was $3.75 \mathrm{~kg}\left(75^{\text {th }}\right.$ to $90^{\text {th }}$ percentile), length $-50 \mathrm{~cm}\left(50^{\text {th }}\right.$ to $75^{\text {th }}$ percentile $)$ with US: LS ratio1.63:1 and head circumference $34 \mathrm{~cm}$ $\left(50^{\text {th }}\right.$ percentile). General examination revealed bilateral post-axial hexadactyly and clinodactyly in the hands with syndactyly of second, third and fourth toes bilaterally with hypoplastic nails in all limbs. Hands and fingers were short. There was a hare-lip with upper lip fused to the upper alveolar margin by multiple frenula. The thorax was long and narrow. Respiratory system examination showed bilateral crackles in the chest; cardiovascular system showed tachycardia and a pansystolic murmur in the left lower sternal border, grade 4/6 clinically consistent with ventricular septal defect. Abdominal examination showed liver palpable $7 \mathrm{~cm}$ and spleen 3 $\mathrm{cm}$ under the respective costal margins. X-rays showed small thoracic cage with horizontally oriented ribs, thickened, irregular costochondral junctions, handle-bar shaped clavicles (Figure 2), shortened humerus and femurs bilaterally, dumb-bell shaped femur with flaring of metaphysis of lower ends of femur, squared iliac wings, flattened acetabulum with three downward projecting spikes (Figure 3). The baby had hypocalcemia and mild derangements in liver function tests. The baby was kept on continuous positive airway pressure and died 48 hours after admission before any other investigations could be performed.

Case 3: An eight years female child, elder sibling of Case 2; having a history of recurrent chest infections till the age of three years, with average intelligence and height of $106 \mathrm{~cm}\left(<3^{\text {rd }}\right.$ centile; expected $\left.124 \mathrm{~cm}\right)$ and US:LS ratio 1.46:1; bilateral post-axial hexadactyly in the hands, clinodactyly, short and stout hands, hypoplastic nails, high-arched palate, absence of upper and lower incisors, conical teeth, fusion of upper lip to alveolar margin and lower lip to lower alveolar margin by multiple prominent frenula (Figure 4). Cardiovascular system, skin and hair were normal. Skeletal survey showed highly placed handle-bar clavicles, acromesomelia of upper and lower extremities, dumb-bell shaped deformity of humerus and femur, mild bowing of humerus with exaggeration of epiphyseal depression by pointed metaphysis of humerus (Figure 5), flattened ilium, decreased angulation of femoral neck, broadening of upper tibial metaphysis, medially placed tibial epiphysis with hypoplasia in its' lateral aspect with notching in the middle (Figure 6), genu vulgam, congenital vertical talus (Figure 6), fusion of capitate and hamate in the hands (Figure 7), postaxial polydactyly (hands), polymetacarpalia, short broad metacarpals with decreased density of bones, normal skull, spine and chest. Other investigations like abdominal sonogram, echocardiogram, liver and renal function tests were normal.

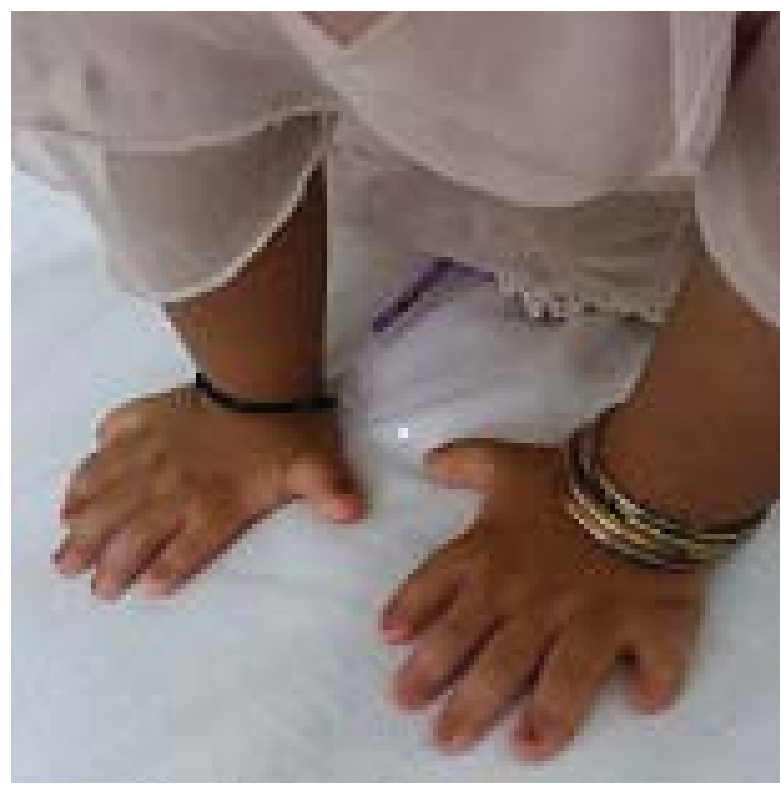

Fig 1: Showing bilateral polydactyly with hypoplastic nails

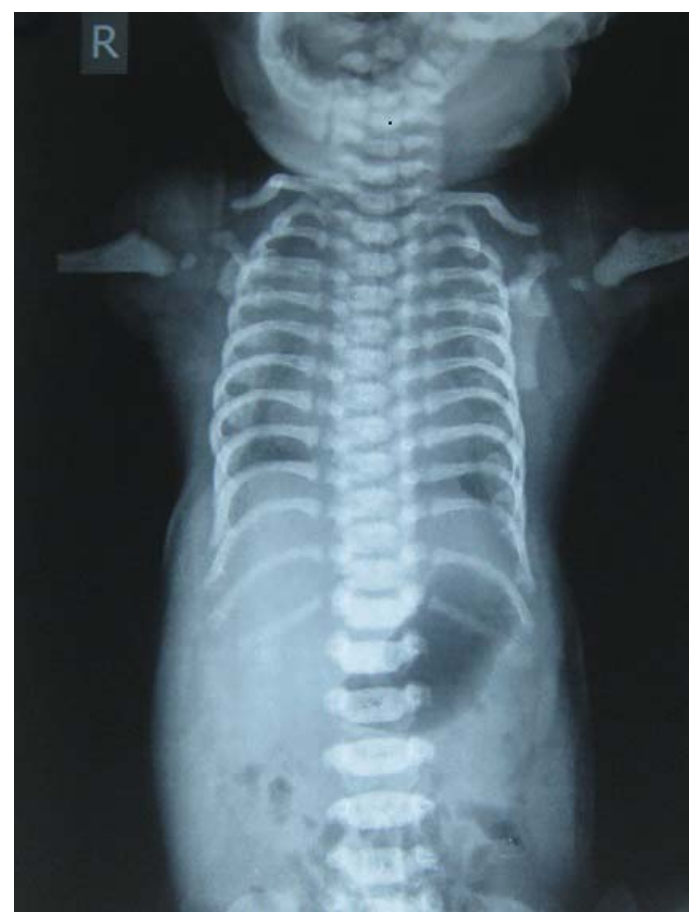

Fig 2: Showing small thoracic cage with handle-bar clavicles 


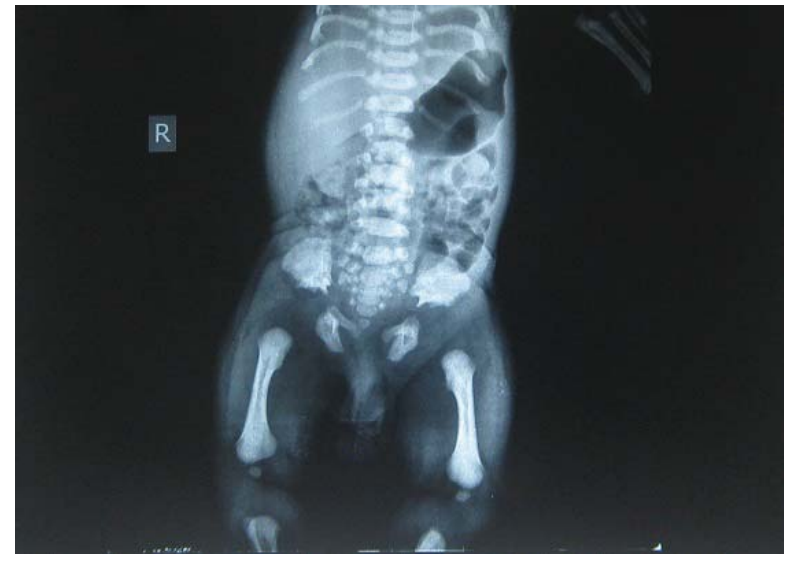

Fig 3: Showing squared ilium with three downward projecting spikes

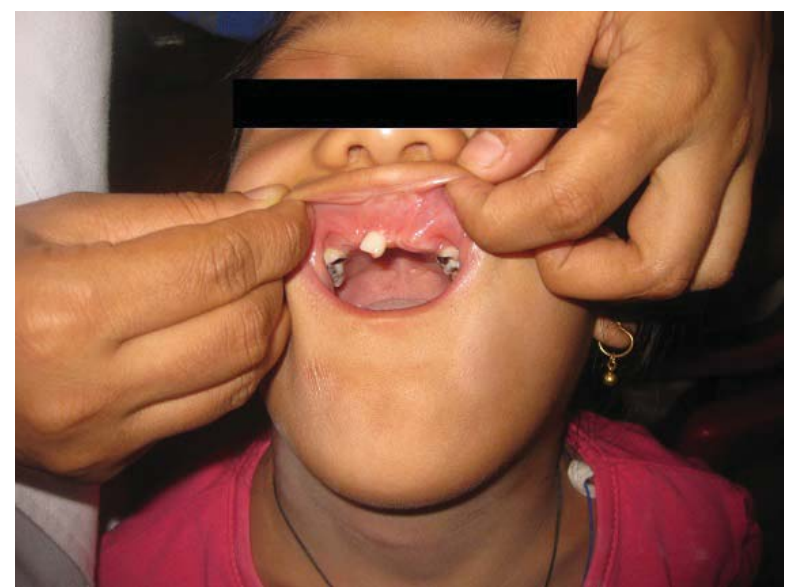

Fig 4: Showing fusion of upper alveolar margin to upper lip by multiple frenula

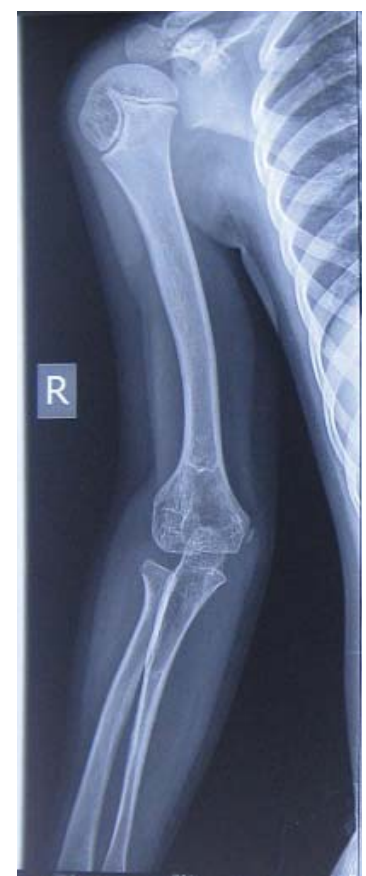

Fig 5: Showing mild bowing of humerus with exaggeration of epiphyseal depression by pointed metaphysis of humerus

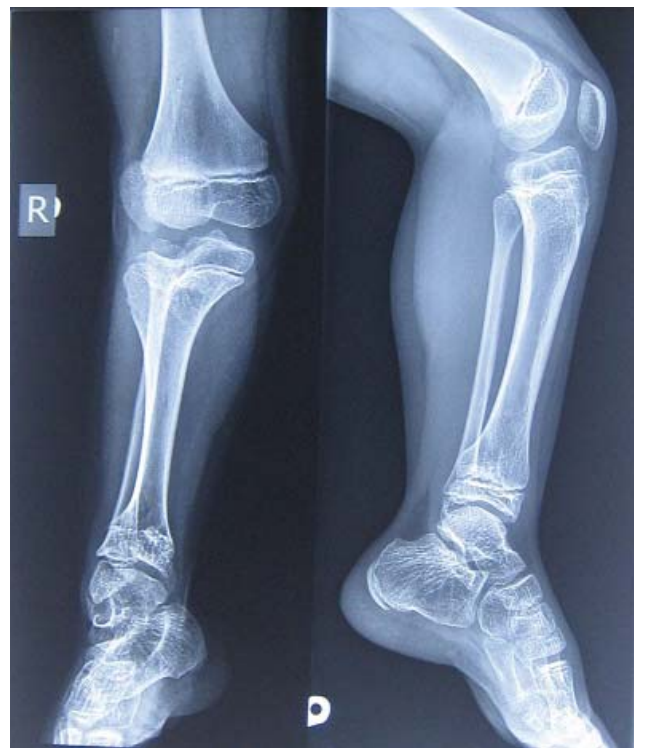

Fig 6: Showing congenital vertical talus- a finding not reported in this case before

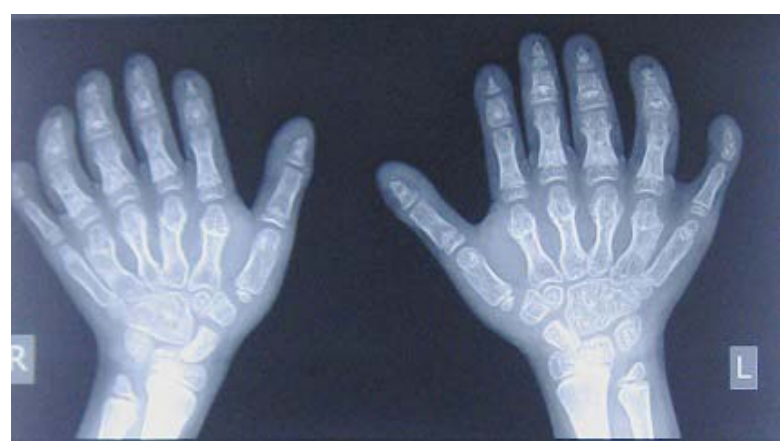

Fig 7: Showing fusion of capitate with hamate along with polydactyly and polymetacarpalia

\section{Discussion}

In 1940, Richard Ellis and Simon van Creveld described a syndrome comprising of chondrodysplasia, bilateral postaxial polydactyly of hands, small and dysplastic extremities and congenital heart defects ${ }^{1}$. They termed the syndrome "Chondroectodermal dysplasia", now known as Ellis van Creveld syndrome (OMIM 225500). In 1933, Mclntosh had described a child with similar features but without heart defect. His case was included in the cases reported by Ellis and van Creveld ${ }^{1}$. Since then, several cases have been described, with and without heart malformations ${ }^{3}$. This is a rare condition; there have been only $\sim 150$ cases reported so far ${ }^{4}$. Of these, ectodermal dysplasia is seen in $\sim 93 \%$ cases. In 1964, McKusick et al reported 52 cases in the Amish community of Lancaster, $\mathrm{Pa}^{4}$. The incidence in the Amish is 5 in 1000 while in the nonAmish population, it is estimated to be 1 in $60,000^{5}$. Today, the syndrome has been found to affect all races especially where consanguinity is practiced ${ }^{3}$. A history 
of consanguinity is found in $30 \%$ cases. Genetic studies have identified mutations in two genes, EVC and LBN (EVC2) located head-to-head on chromosome 4p16.2.4 which produce similar clinical manifestations with variable expression $n^{4,6,7}$.

EvC syndrome presents with a characteristic tetrad:

1. Disproportionate dwarfism. Short stature may be present at birth or becomes more apparent with subsequent growth. Surviving adults have an ultimate stature of $110-150 \mathrm{cms}$. The severity of limb shortening increases from the proximal to the distal portions

2. Bilateral postaxial polydactyly ( $100 \%$ cases) of the hands, occasionally toes (10\%)

3. Ectodermal dysplasia with dystrophic, small nails, thin sparse hair, hypodontia and abnormally formed teeth

4. Congenital cardiac malformations in $50 \%$ to $60 \%$ of cases, the most common being a single atrium and a ventricular septal defect. Congenital heart defect is considered to be the least constant of the tetrad ${ }^{3}$. Half of these children die during infancy because of cardiovascular-related complications. Several authors have reported cases where cardiac defect is absent leading to normal life spans ${ }^{8-11}$. In our case, two of three cases did not have an associated cardiac defect.

The most consistent oral manifestations are: fusion of the upper lip to the maxillary gingival margin, causing a slight V-notch in the middle (hare-lip). The anterior portion of the lower alveolar margin is serrated and multiple small labial frenula are present. Teeth tend to be small and conical, molars have abnormal cusps or accessory grooves and enamel may be hypoplastic. Other abnormalities such as genu valgum, genitourinary, hepatic, renal and CNS abnormalities are occasionally seen. The skin and sweat glands are usually normal. Most patients have average intelligence.

The chief differential diagnosis includes Jeune syndrome, McKusick-Kauffman syndrome and Weyer's syndrome. Distinguishing features are significant respiratory distress, less severe short stature, renal and hepatic involvement, absence of ectodermal dysplasias and heart defect in Jeune syndrome ${ }^{12}$. Our second case (Case 2) had several features suggestive of Jeune syndrome; in addition he also had a cardiac defect and ectodermal defects which went in favour of EvC syndrome. McKusick-Kauffman syndrome can be differentiated by the presence of hydrometrocolpos.
Weyer's syndrome, in addition to facial abnormalities has many features similar to that of EvC syndrome but of a milder nature and is inherited in autosomal dominant manner. In some cases, there may be overlapping features of all these syndromes. The syndrome can be diagnosed in-utero from $18^{\text {th }}$ week of gestation by ultrasound ${ }^{4,7,13-14}$. Increased fetal nuchal translucency at $13^{\text {th }}$ week has also been associated with $\mathrm{EvC}^{14}$. Definitive diagnosis is molecular genetic testing for mutation of EVC and EVC2 gene ${ }^{4}$. Radiological findings suggestive of EvC syndrome are: narrow thoracic cage with short, horizontally aligned ribs, progressive distalward shortening of the long bones with slight curvature of humerus, dumb-bell appearance of metaphysis of lower ends of long bones, postaxial polydactyly of hands, polymetacarpalia, fusion of the hamate and capitate in older children, cone-shaped epiphysis of proximal phalanges, short broad middle phalanges with hypoplastic distal phalanges; premature ossification of femoral epiphysis at birth, short iliac wings with flattened acetabuli and hook-like downward projecting spikes on its' medial and lateral aspects ${ }^{3,7,15}$. There can be hypoplasia of lateral proximal tibial ossification centres and exostosis at medial aspect of proximal tibia ${ }^{3,7}$. The metaphyseal border of the tibia appears angulated in the form of a double-sloped roof, with the outer slope being longer than the inner- this finding is considered to be pathognomonic of EvC syndrome ${ }^{8}$. All three of our cases had the radiological features suggestive of EvC syndrome, with the third case having the pathognomonic feature of tibial plateau deformity and carpal bones fusion with polymetacarpalia. In addition, she also had congenital vertical talus which has not been reported in other cases of EvC syndrome.

Management of a child with EvC syndrome is multidisciplinary; care should be provided by the neonatologist, odontologist, cardiologist/ cardiothoracic surgeon, orthopaedic surgeon for correction of bony deformities etc. The longevity usually depends on the presence of cardiac lesion. Growth hormone therapy for short stature has to be considered although it was found to be ineffective by some authors ${ }^{4}$. Genetic counselling is important as the recurrence risk in the next pregnancy is $25 \%$.

\section{Conclusion}

EvC syndrome is a rare condition. Here we reported three cases in children from the same community and ethnicity. Genetic testing is necessary in these ethnic groups in order to identify the pocket of population in Nepal having the mutated gene. 


\section{References}

1. Ellis RW, van Creveld S. A syndrome characterized by ectodermal dysplasia, polydactyly, chondrodysplasia and congenital morbus cordis. Report of three cases. Arch Dis Child 1940;15:65-84.

2. Nainby-Luxmoore JC. Ellis-van Creveld Syndrome, (Chondroectodermal Dysplasia Syndrome) in a Gurkha Family. JR Army Med Corps 1988;134:12627.

3. Ellis RW, Andrew JD. Chondroectodermal dysplasia. J Bone Joint Surg 1962;44:626-36.

4. Baujat G, Le Merrer M. Ellis van Creveld syndrome. Orphanet J Rare Dis 2007;2:27.

5. D'Asdia MC, Torrente I, Consoli F, Ferese R, Magliozzi $M$, Bernardini L, et al. Novel and recurrent EVC and EVC2 mutations in Ellis van Creveld syndrome and Weyer's acrofacial dysostosis. Europ J Med Genet 2013;56:80-87.

6. Ruiz-Perez VL, Goodship JA. 2009. Ellis-van Creveld Syndrome and Weyer's Acrodental Dysostosis Are Caused by Cilia-Mediated Diminished Response to Hedgehog Ligands. Am J Hum Genet Part C Semin Med Genet 151C:341-351.

7. Muensterer OJ, Berdon W, McManus C, Oestreich A, Lachman RS, Cohen Jr. MM, et al. Ellis-van Creveld syndrome: its history. Pediatr Radiol 2013;43:103036.

8. Ferrero NA, Pozo OO, Morresi ES. ChondroEctodermal Dysplasia (Ellis van-Creveld syndrome). Report of a case and review of the literature. J Bone and Joint Surgery 1961; 43A(8):1230-236.
9. Alves-Pereira D, Berini-Aytés L, Gay-Escoda C. Ellis-van Creveld Syndrome. Case Report and Literature Review. Med Oral Patol Oral Cir Bucal 2009;14(7):E340-3.

10. Khan I, Ahmed SA, Mohsin K. Ellis van-Creveld Syndrome. A case report. J Pak Assoc Dermatol 2006;16:239-42.

11. Kayal L, Jayachandran S, Singh KS. Chondroectodermal Dysplasia (Ellis vanCreveld Syndrome ): A Case Report with Dental Considerations and Review of Literature. Internal Med: Open Access 2012;2:104.doi:10.4172/21658048.1000104.

12. de Vries J, Yntema JL, van Die CE, Crama N, Cornelissen EAM, Hamel BCJ. Jeune Syndrome: description of 13 cases and a proposal for follow-up protocol. Eur J Pediatr 2010;169(1):77-88.

13. Chen CP, Chen CY, Chern SR, Su JW, Wang W. Firsttrimester prenatal diagnosis of Ellis-van Creveld syndrome. Taiwan J Obstet Gynaecol 2012;51:64348.

14. Venkat-Raman N, Sebire NJ, Murphy KW, Carvalho JS, Hall CM. Increased first-trimester fetal nuchal translucency thickness in association with chondroectodermal dysplasia (Ellis- van Creveld Syndrome).Ultrasound Obstet Gynecol 2005;25:41214.

15. Cremin BJ, Beighton P. Dwarfism in the newborn: the nomenclature, radiological features and genetic signifance. British J Radiology 1974;47(554):77-93. 